\title{
Pediatric patient classification system: improvement of an instrument
}

\author{
SISTEMA DE CLASSIFICAÇÃO DE PACIENTES PEDIÁTRICOS: APERFEIÇOAMENTO DE \\ UM INSTRUMENTO
}

\section{SISTEMA DE CLASIFICACIÓN DE PACIENTES PEDIÁTRICOS: PERFECCIONAMIENTO DE UN INSTRUMENTO}

\author{
Ariane Polidoro Dini ${ }^{1}$, Edinêis de Brito Guirardello²
}

\begin{abstract}
Objective: Improve the content validity of the instrument for classification of pediatric patients and evaluate its construct validity. Method: A descriptive exploratory study in the measurement of the content validity index, and correlational design for construct validation through exploratory factor analysis. Results: The content validity index for indicators was 0.99 and it was 0.97 for graded situations. Three domains were extracted in the construct validation, namely: patient, family and therapeutic procedures, with $74.97 \%$ of explained variance. The instrument showed evidences of content and construct validity. Conclusion: The validation of the instrument occurred under the approach of familycentered care, and allowed incorporating some essential needs of childhood such as playing, interaction and affection in the content of the instrument.
\end{abstract}

\section{DESCRIPTORS}

Health evaluation

Pediatric nursing

Workload

Classification

Validation studies

\section{RESUMO}

Objetivo: Aprimorar a validade de conteúdo do instrumento de classificação de pacientes pediátricos e avaliar a sua validade de constructo. Método: Estudo com delineamento descritivo exploratório na mensuração do índice de validade de conteúdo e delineamento correlacional para a validação de construto por meio de análise fatorial exploratória. O índice de validade de conteúdo para os indicadores foi 0,99 e para as situações graduadas de 0,97 . Resultados: Na validação do construto, foram extraídos três domínios: paciente, família e procedimentos terapêuticos, com $74,97 \%$ de variância de explicação. $O$ instrumento apresentou evidências de validade de conteúdo e de construto. Conclusão: A validação do instrumento ocorreu sob a abordagem do cuidado centrado na família e permitiu incorporar algumas necessidades essenciais da infância como brincadeiras, interação e afeto ao conteúdo do instrumento.

\section{DESCRITORES \\ Avaliação em saúde \\ Enfermagem pediátrica \\ Carga de trabalho \\ Classificação \\ Estudos de validação}

\section{RESUMEN}

Objetivo: Perfeccionar la validez de contenido del instrumento de clasificación de pacientes pediátricos y evaluar su validez de constructo. Método: Estudio con diseño descriptivo exploratorio en la mensuración del índice de validez de contenido y diseño correlacional para la evaluación de constructo por medio de análisis factorial exploratorio. El índice de validez de contenido para los indicadores fue 0,99 y para las situaciones graduadas, 0,97. Resultados: En la validación del constructo, fueron extraídos tres dominios: paciente, familia y procedimientos terapéuticos, con el $74,97 \%$ de variación de explicación. El instrumento presentó evidencias de validez de contenido y de constructo. Conclusión: La validación del instrumento sucedió bajo el abordaje del cuidado centrado en la familia y permitió incorporar algunas necesidades esenciales de la infancia como juegos, interacción y afecto al contenido del instrumento.

\section{DESCRIPTORES \\ Evaluación en salud \\ Enfermería pediátrica \\ Carga de trabajo \\ Clasificación \\ Estudios de validación.} Extracted from the thesis "Validação do instrumento de classificação de pacientes pediátricos", Universidade Estadual de Campinas, $2013 .{ }^{1} \mathrm{PhD}$ in
Nursing, Universidade Estadual de Campinas, Campinas, SP, Brazil. ${ }^{2}$ Associate Professor, Faculty of Nursing, Universidade Estadual de Campinas,
Campinas, SP, Brasil. 


\section{INTRODUCTION}

The increasing complexity in pediatric hospitalizations defies nursing to implement strategies of a model of care no longer exclusively dedicated to the disease or the patient and their development, but also with the family as the focus of care ${ }^{(1-4)}$. Thus, studies indicate the importance of measuring the workload and associate the real need in relation to quantity and qualifications of nursing professionals, the care profile of pediatric inpatient units and the quality of nursing care ${ }^{(5-8)}$.

The staff dimensioning, that allows the balance between the need for nurses and the demand for care, requires the measurement of workload, among other variables, and this can be inferred through the Patient Classification System ${ }^{(8)}$. The use of instruments for patient classification enables the characterization of inpatient units that, in addition to base the staff dimensioning, may support the prediction of material and financial resources, and promote the improvement of skills and the team involvement ${ }^{(9-10)}$.

In 2013 was published a specific instrument for patient classification of the pediatric clientele ${ }^{(11)}$, composed of 11 indicators, each with four situations of care dependency, graded from one to four points, in ascending order of care need. The Pediatric Patient Classification Instrument (PPCl) enables the classification of patients into five categories of care: Minimum, Intermediate, High Dependency, Semi-intensive and Intensive ${ }^{(12)}$.

The use of the PPCl(11) in care and management practice as well as in validation studies, highlights the need to improve the content of the instrument, since the validity (related to accuracy), is a prerequisite for the reliability of the instrument measures ${ }^{(5,13-16)}$. Thus, this study aimed to improve the content validity of the instrument for classification of pediatric patients, and evaluate the construct validity of the refined instrument.

\section{METHOD}

This is study of mixed methods, with descriptive and exploratory design for content validation, and correlational design for construct validation. Data collection for validation of content and construct occurred simultaneously between June and November 2012. The study was approved by the Research Ethics Committee with the exemption of signature of the Free and Informed Consent. This was justified by the use of PPCI being inherent in the work process of nursing professionals and because patients are not subjected to any procedure as a function of the instrument (Process number 646/2010).

\section{Content validation: Content Validity Index}

Firstly, an electronic mail was sent to seven nurses with experience or familiarity on application of the instrument.
The email explained the purpose of the research, had the PPCl file attached, and the following question: Which changes do you suggest in the Instrument for Classification of Pediatric Patients: Would you add or remove any indicator, alter any score, add a new indicator, add another situation, remove or add another score?

Five nurses replied the email with suggestions which, associated to another validity study of the $\mathrm{PPCl}^{(5)}$, subsidized the content reformulations of the instrument. The modified version of the $\mathrm{PPCl}$ was submitted for consideration by experts to measure the Content Validity Index (CVI).

The CVI is a method that employs Likert scales in a questionnaire to assess the relevance and clarity of the content of the instrument ${ }^{(15-16)}$. This method allows analyzing each item individually, the instrument as a whole, and measuring the proportion of experts who agree with the content of the instrument.

The desired number of experts to measure the CVI must be greater than five and the choice of professional derives from the researcher's confidence ${ }^{(15)}$. In total, 14 professionals of assistance, management, faculty and researchers in the field of pediatric nursing were invited to participate in this study. The guests received specific instructions on how to perform the evaluation by email. The research purposes, the original version and the proposal for the $\mathrm{PPCl}$ were presented. They were asked to evaluate the content of the instrument using a Likert scale: (1) Not relevant or representative; (2) Needs major revision to be representative; (3) Item requires minor revision to be representative; and (4) Relevant and representative item. The index score was calculated using the formula:

$$
\mathrm{CVI}=\frac{\sum \text { number of answers } 3 \text { or } 4}{\text { Total Number of answers }}
$$

Eight nurses replied the email, which is an appropriate number of judges for considering the content of the PPCl as validated. Therefore, was followed the methodological recommendation that the CVI must be greater than $0.78^{(15-16)}$.

\section{Exploratory factor analysis: assessment of construct validity}

The sample included 227 pediatric patients hospitalized between July and November 2012. Data collection occurred in two stages; the first one was from July to September, with classification of 166 patients, and the second was from October to November, with classification of 61 patients. It was carried out by the first author of the study with a spreadsheet log comprising information about age, reason for admission and classification of each patient according to the $\mathrm{PPCl}^{(9-10)}$. Data were organized in a spreadsheet in Microsoft Excel and analyzed with the SPSS $20.0^{\circ}$ for Windows.

Construct validity was assessed by Exploratory Factor Analysis (EFA). All variables were ordinal and the chosen 
method for factor extraction was by principal components with orthogonal Varimax rotation. According to the methodological recommendation, was considered a ratio of five patients per PPCl indicator ${ }^{(13-14)}$. The test of KaiserMeyer-Olkin (KMO), with accepted values greater than 0.60 , and the Bartlett's sphericity test with less than 0.05 significance, were considered to check the fit of the data to the EFA ${ }^{(17-18)}$. The construct validation by EFA was made by analysis of the total variance explained (VE), which must be greater than $60 \%$; by the commonality values representatives of the VE proportion for each indicator by the identified factors, and must be greater than 0.60 ; and by the factor loadings that represent the correlation between the indicator and the extracted factor, that must have values greater than $0.30^{(17-18)}$.

\section{RESULTS}

\section{Content validation}

In June 2012, five nurses replied the e-mail (71.42\% of the invited), with time since graduation ranging between 4 and 28 years; three of these worked in management and two in pediatric nursing care. The five professionals had specialization titles, two in the Management area, one with a multidisciplinary residence, and two with the title of specialist in Pediatric Nursing. One of the nurses simultaneously attended her Doctorate Program in Nursing and her Specialization Program in Stomatherapy.

They presented the following suggestions: Replace Capacity by Possibility or Necessity; delete all gerund tenses; contemplate in Activity the interaction with the family and the team, problems with hearing and visual acuity, the mood and the willingness to play; contemplate in Assessment of physiological controls the monitoring by any equipment as four points; consider in Cutaneous and mucosal integrity, the complexity of the dressing; contemplate infusion pumps as four points in Drug therapy, and differentiate the administration of oral medications for uncooperative patients; make the indicators Eliminations and Personal hygiene more objective by eliminating the number of professionals, and considering tubes and ostomies as four points; in Feeding and hydration, include fasting and the need for intravenous hydration as four points, and differentiate uncooperative patients for oral administration; in Participation of the accompanying person, consider cultural issues and learning possibilities, and the attitude regarding care; and in the indicator Support network and family support, consider the involvement of the companion with the plan of care for the pediatric patient.

Eight nurses participated ( $57.14 \%$ of the invited) of the second stage of the study, between August and September 2012. Their time since graduation ranged between three and 28 years. Among these professionals, three worked in management, three in support of Pediatric Nursing care, and two in Teaching (one in middle-level vocational education, and the other at the University). Regarding professional qualification, four nurses had specialization titles, one in Management and three in Pediatric Nursing. Two nurses were PhD students and one already had a PhD in Nursing.

The CVI found was equal to 1 (one) for the title, conceptual definitions and graded situations of nine indicators. Participation of the accompanying person presented $\mathrm{CVI}$ equal to one (1) for the title and conceptual definition, and 0.88 for the composition of graded situations. Cutaneous and mucosal integrity showed CVI equal to 0.88 for title and conceptual definition, and 0.75 for the composition of graded situations. Thus, the refined $\mathrm{PPCl}$ showed $\mathrm{CVI}$ equal to 0.99 for the titles and conceptual definitions and 0.97 for the composition of graded situations.

Besides the validity evaluation measured by the CVI, the experts pointed out new suggestions for refinement of indicators: in the indicator Activities, contemplate language and feelings like anger, sadness, agitation; replace the term Acuity by Deficiency, add Apathy in three points and Severe cerebral palsy in four points; in Assessment of physiological controls, add peritoneal dialysis in the statement, and in four points, add continuous monitoring; in Feeding and hydration, add effective breastfeeding at one point and ineffective in three points; in Eliminations, add training sphincters in three points; in Personal hygiene, discriminate performing alone at one point, partial assistance in two points and total assistance in three points; in Mobility and ambulation, replace ambulation with assistance by direct supervision in three points; in Cutaneous and mucosal integrity, better define care and dressings of low, medium and high complexity; in Participation of the accompanying person add psychiatric syndrome in four points and delete proactive and reactive postures; in Support network and family support, consider that family touch can be considered an intervention.

\section{Construct validation}

In total, 166 patients were classified between July and September 2012, and 62 (37.3\%) were younger than one year, $60(36.2 \%)$ were aged between one and six years, 31 (18.7\%) between seven and eleven years; 12 (7.2\%) between twelve and seventeen years and one patient was older than 18 years. The main reasons for admission were the following: $27.7 \%$ for respiratory diseases; $24.1 \%$ for surgical procedures; $13.3 \%$ for genitourinary disorders; $13.3 \%$ for infections; $6 \%$ for neurological disorders; $2.4 \%$ for disorders of the gastrointestinal tract; $2.4 \%$ for orthopedic conditions; and $10.8 \%$ for other reasons (diagnostic procedures, malnutrition, dehydration, accidents, rheumatologic disorders, dermatologic and hematologic). According to the $\mathrm{PPCl}, 5 \%$ of patients were classified as minimum care, $26 \%$ as intermediate care, $36 \%$ as high dependency, $11 \%$ as semi-intensive and $22 \%$ as intensive care.

The Bartlett's sphericity test obtained $p<0.001$ and $\mathrm{KMO}$ values for all indicators were greater than 0.84 .
Pediatric patient classification system: improvement

of an instrument

Dini AP, Guirardello EB 
The EFA extracted only two domains, with $70.52 \%$ of $V E$, being: Nursing interventions and monitoring (58.67\% VE) and Patient Needs (11.85\% VE). The values of commonal- ity and factor loading are shown in table 1. After the EFA, the suggested modifications were followed and the PPCI took its beta version (Chart 1).

Table 1 - Analysis of the construct of the PPCI - Campinas, 2012

\begin{tabular}{lcc}
\hline $\begin{array}{l}\text { Construct } \\
\text { Domain: Patient Needs }\end{array}$ & Commonality & Factor loading \\
\hline Personal hygiene & 0.89 & 0.83 \\
Feeding and hydration & 0.65 & 0.74 \\
Mobility and ambulation & 0.86 & 0.83 \\
Eliminations & 0.68 & 0.82 \\
\hline Domain: Nursing interventions and monitoring & & 0.85 \\
Support network and family support & 0.74 & 0.85 \\
Participation of the accompanying person & 0.75 & 0.74 \\
Oxygenation & 0.76 & 0.74 \\
Assessment of physiological controls & 0.66 & 0.68 \\
Activity & 0.56 & 0.68 \\
Cutaneous and mucosal integrity & 0.56 & 0.68 \\
Drug therapy & 0.50 & \\
\hline
\end{tabular}

Note: $(n=166)$

Chart 1 - Pediatric Patient Classification Instrument (beta version) ${ }^{*}$

\section{Domain: Family}

Participation of the accompanying person: Attitude and performance of the accompanying person in caring for pediatric patients and meeting their needs.

1- The accompanying person recognizes the physical and emotional needs of the patient and can meet them.

2- The accompanying person demonstrates willingness to incorporate new information and skills to care for the pediatric patient.

3- The accompanying person demonstrates difficulty or unwillingness to incorporate new information and skills to care for pediatric patients AND / OR presents anxiety and / or fear and / or anger and / or self-restraint.

4- The accompanying person is missing or shows aggression or unwillingness to care for the patient and / or patient requiring technical care of high complexity.

Support network: Possibility of incorporating the knowledge, values, beliefs and culture of the accompanying family in planning and providing care to pediatric patients during their hospital stay.

1- Presence of an accompanying person involved in planning and providing care during the entire time.

2- Presence of an accompanying person involved in planning and providing care for more than 12 hours a day.

3- Presence of an accompanying person involved in planning and providing care for less than 12 hours a day.

4- Lack of family support OR Presence of accompanying person with psychiatric disease OR Presence of an accompanying person that shows stress or alienation in the care for patient.

\section{Domain: Patient}

Activity: Possibility of interacting with family members, professionals or patients and carrying out activities consistent with the development expected for their age.

1- Showing affection with the family and interest to stimuli and activities consistent with the age group, such as playing, games, reading or monitoring of the school curriculum.

2- Showing affection with the family and interest to stimuli, with limitation to carry out activities consistent with the age group, such as playing, games, reading or monitoring of the school curriculum.

3- Disinterest to stimuli by pain, sadness, anger, psychomotor agitation or apathy; language difficulties; visual impairment or deficit in development.

4- Severe cerebral palsy or coma vigil or unconscious or totally sedated.

Oxygenation: Possibility of the child or adolescent maintaining permeability of airway, ventilation and normal oxygenation.

1- Spontaneous breathing, without need for oxygen therapy or airway clearance.

2- Spontaneous breathing, with need for airway clearance by instillation of saline.

3- Spontaneous breathing with need for airway clearance by aspiration of secretions and / or need for oxygen therapy.

4- Mechanical ventilation (Non-invasive or invasive). 
Continuation...

\section{Domain: Patient}

Mobility and ambulation: Ability of pediatric patients to mobilize body segments and walk safely.

1- Ambulation without assistance.

2- Bed rest and moves without assistance.

3- Bed rest and moves with assistance OR ambulates with direct supervision.

4- Bedridden, entirely dependent for change in decubitus.

Feeding and hydration: Possibility of the child or adolescent receiving fluids and nutrients intake, or enteral or parenteral infusion.

1- Oral route independently or effective breastfeeding.

2- Oral route with assistance and cooperative patient.

3- Tubes (gastric, enteral or gastrostomy) or oral route with uncooperative patient or with risk of aspiration or ineffective breastfeeding.

4- Parenteral nutrition/hydration

Eliminations: Conditions of pediatric patients to perform urinary and intestinal excretion.

1- Toilet without assistance.

2- Toilet with assistance.

3- Diapers or Training of sphincters OR Bedpan or urinal.

4- Intravesical catheter or stomas.

Personal hygiene: Possibility of pediatric patients performing alone, needing assistance, direct supervision or totally depending for oral and body hygiene, and dressing.

1- Aspersion bath without assistance.

2- Aspersion bath with partial assistance.

3- Immersion bath or aspersion chair bath or with total assistance.

4- Bed bath or Bath in the incubator or in heated cot.

Domain: Therapeutic procedures

Assessment of physiological controls: Need for observation and control of data such as vital signs, O2 saturation, central venous pressure, blood glucose, peritoneal dialysis, fluid balance.

$1-6 / 6$ hours.

2- 4/4 hours.

3- 2/2 hours.

4-Interval shorter than two hours or continuous monitoring.

Drug therapy: Need of the child or adolescent to receive medication.

1- No need for medication.

2- Need for medication by topic, ocular and/or oral route with collaborative patient.

3- Drugs by parenteral route, enteral route, inhalation, or topical, ocular or oral with uncooperative patient.

4- Blood products and / or chemotherapy and / or Absolute indication for use of an infusion pump.

Cutaneous and mucosal integrity: Need for maintaining or restoring the mucous and cutaneous integrity.

1 - Intact skin throughout the body area.

2- Need for LOW complexity care, such as skin hydration, treatment of simple dermatitis, renovation of peripheral venous catheter fixation.

3- Need for MEDIUM complexity care, such as dressings in wounds limited to the dermis, insertion of drains, tracheostomy, gastrostomy or central venous catheter.

4- Need for HIGH complexity care, such as debridement, disseminated dermatitis, extensive burns; complex stomas or wounds with visualization of muscle fascia, bone or eviscerations.

* The evaluator should choose the situation that best describes the conditions of pediatric patients and compare the final score to the scale: 11-17 points=Minimum; 18-23 points=Intermediate; 24-30 points= High dependency; 31-36 points= Semi-Intensive; 37-44 points=Intensive .

\section{Construct validation of the beta version of PPCI}

Between October and November 2012, 61 pediatric patients were classified, namely: 18 (29.5\%) were younger than 1 year, $22(36.1 \%)$ were aged between 1 and 6 years, 10 (16.4\%) between 7 and 11 years, 10 (16.4\%) between 12 and 17 years, and 1 (1.6\%) was over 18 years. The main reasons for hospitalization were: $26.2 \%$ for respiratory diseases; $16.4 \%$ for neurological disorders; $13.1 \%$ for medical conditions (malnutrition, dehydration, rheumatologic, dermatologic and hematologic disorders), 9.8\% for surgical procedures, $9.8 \%$ for orthopedic conditions, $8.2 \%$ for infections, $6.7 \%$ for genitourinary disorders and $9.8 \%$ for other reasons (diagnostic procedures and accidents). According to the refined $\mathrm{PPCl}, 7 \%$ of patients were classified as minimal care, $21 \%$ classified as intermediate care, $39 \%$ as high dependency, $23 \%$ as semi-intensive and $10 \%$ as intensive care. 
The Bartlett's sphericity test obtained $p<0.001$ and the $\mathrm{KMO}$ values for all the indicators were greater than 0.62 . The EFA extracted three domains, with $74.97 \%$ of VE, be- ing: Patient (51.88\% VE), Family (14.91\% VE) and Therapeutic procedures ( $8.18 \% \mathrm{VE})$. The commonalities and factor loadings are shown in table 2.

Table 2 - Analysis of the construct of the beta version of PPCI - Campinas, 2012

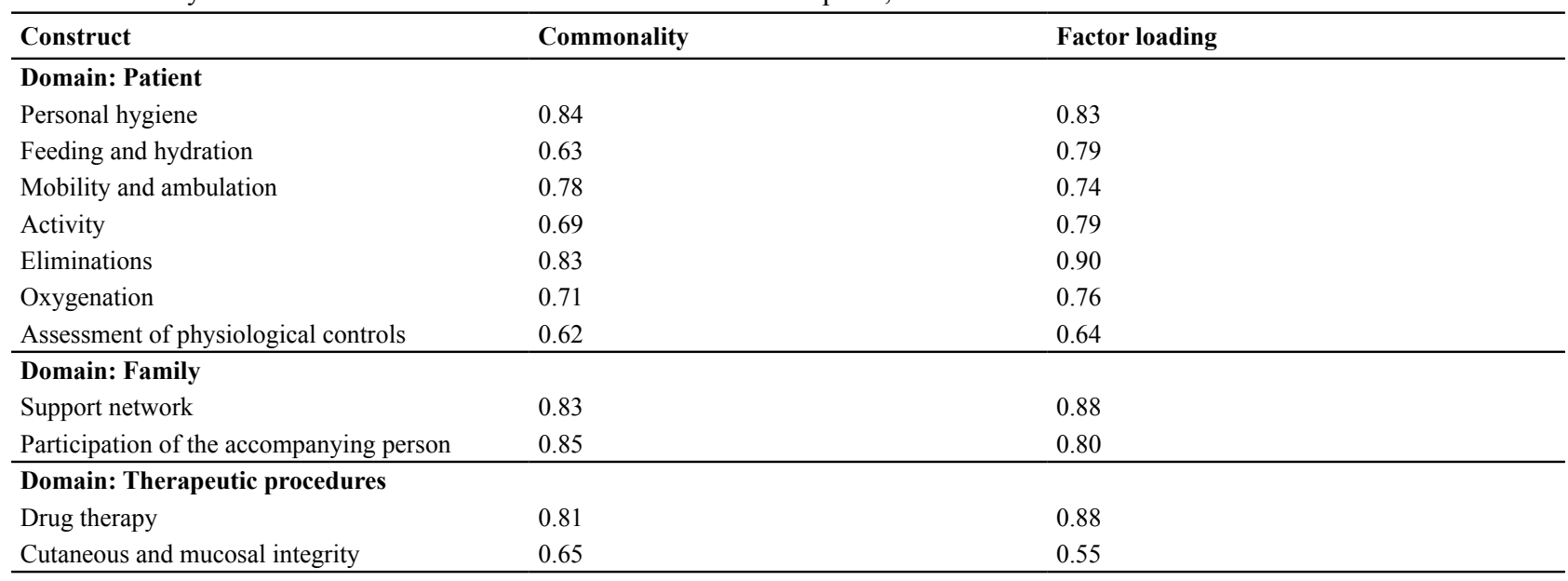

Note: $(n=61)$

\section{DISCUSSION}

The participation of nurses with experience in applying $P P C I^{(11)}$, and with different time since graduation, diverse experiences in care, teaching or management in both phases of content validation, allowed addressing all indicators, from the statements and conceptual definition until graded situations.

The construction of an intermediate version of the $\mathrm{PPCl}$, after the first phase of content validation and EFA, which resulted in only two domains with commonalities lower than 0.6 for the indicators Activity, Cutaneous and mucosal integrity, and Drug therapy, pointed to the inadequacy of the extracted model. Unlike the previous study, when three domains were extracted from pediatric nursing care $^{(5)}$.

When carefully analyzing the sample, it was found that the text of the indicators Participation of the accompanying person and Support network and family support induced some misconceptions of evaluation of pediatric nursing care by disregarding that interactions with parents or significant people for the child could be considered as a health intervention ${ }^{(1-2,19)}$.

The continuity of the content validation process of the $\mathrm{PPCl}$ allowed improving the description of indicators and graded situations, as well as rearranging the instrument in a sequence of domains to promote the assessment of patients in order, while members of a family (domain: Family); to focus on their needs while developing individuals (domain: Patient); and, finally, to focus on the needs for care derived from pathology (domain: Therapeutic procedures).

The evidence of content validity lies in its analysis by experts in the field, with the CVI measurement of 0.99 for indicators and 0.97 for the graded situations ${ }^{(15-16)}$ and relied on the suggestions made by nurses involved in the care, teaching and research. Thus, the revision of indicators in accordance with the suggestions of experts provided the beta version of the PPCl shown in table 1 , and with this version were carried out the second data collection and EFA.

The results of the second EFA showed consistency with the content validation of the instrument, because just like in the previous study ${ }^{(5)}$, three factors were identified, i.e. domains: Family, Patient and Therapeutic procedures. This finding is important because content validity is a prerequisite for the other types of validity ${ }^{(15-16)}$, thus, the simultaneous validation of content and construct allowed evaluating the validity of the instrument in a complementary way.

The three domains extracted by the EFA of the beta version of $\mathrm{PPCl}$ do not represent a sum of caregiving tasks or individual procedures, but nursing values grounded in the notion that the patients' needs are multidimensional and depend on complex objective and subjective interactions $^{(10)}$. Thus, the workload can be estimated by the PPCl when classifying in categories of care and associating the number of nursing hours ${ }^{(8)}$. With this, they do not reflect in a Taylorist way ${ }^{(20)}$ the nursing practice, by not reducing to simple tasks the complex interactions of pediatric nursing care, either with patients or their families.

The improvement of PPCl allowed incorporating some essential needs of childhood such as playing, interaction and affection in the content of the instrument and hence, improve its validity of content and construct.

The limitations of the study were: the methodology for validation of content, derived from the reliability of the researcher ${ }^{(15)}$; and the incorporation of the indicator As- 
sessment of physiological controls in the Patient domain of the EFA, contradicting the previous study ${ }^{(5)}$.

Additional studies are recommended to associate the age of development with the care category, as well as studies to associate the number of nursing hours to serve every category of care with safety and quality.

\section{CONCLUSION}

This study allowed improving the content validity of $\mathrm{PPCl}$, approaching it of the possibility to evaluate the practice of pediatric nursing from the perspective of familycentered care. The concomitant evaluations of construct and content validity were able to promote complementarity in the refinement of $\mathrm{PPCl}$.

\section{REFERENCES}

1. Sieben-Hein D, Steinmiller EA. Working with complex care patients. J Pediatr Nurs. 2005;20(5):389-95.

2. Hutchfield K. Family-centred care: a concept analysis. J Adv Nurs. 1999;29(5):1178-87.

3. Pinto JP, Ribeiro CA, Pettengill MM, Balieiro MMF. Cuidado centrado na família e sua aplicação na enfermagem pediátrica. Rev Bras Enferm 2010;63(1):132-5.

4. Hobson L, Noyes J. Fatherhood and children with complex healthcare needs: qualitative study of fathering, caring and parenting. BMC Nurs. 2011;10:5.

5. Dini AP, Santos DFA, Oliveira HC, Guirardello EB. Validity and reliability of a pediatric patient classification instrument. Rev Latino Am Enfermagem. 2014;22(4):598-603.

6. Mark BA, Harless DW, Berman WF. Nurse staffing and adverse events in hospitalized children. Policy Polit Nurs Pract. 2007;8(2):83-92.

7. Aiken LH, Cimiott JP, Sloane DM, Smith HL, Flynn L, Neff DF. The effects of nurse staffing and nurse education on patient deaths in hospital with different nurse work environments. Med Care. 2011;49(12):1047-53.

8. Fugulin FMT, Gaidzinski RR, Castilho V. Dimensionamento de pessoal de enfermagem em instituições de saúde. In: Kurcgant $P$, coordenadora. Gerenciamento em enfermagem. Rio de Janeiro: Guanabara Koogan; 2010. p.121-35.

9. Giovannetti P. Understanding patient classification systems. J Nurs Adm. 1979;9(2): 4-9.

10. De Groot HA. Patient classification system evaluation. Part 1: essential system elements. J Nurs Adm. 1989;19(6):30-5.
The use of the instrument version validated in this study is recommended to classify pediatric patients, directing the evaluation of nurses in a model of care focused on children and their families to promote health in hospitals.

The validation process of measuring instruments is complex and multifaceted due to the required abstraction to assign numbers to the representation of theoretical, practical and empirical concepts. Thus, it cannot be static, but requires the involvement of researchers for monitoring the validity and reliability of the instrument. Hence, further studies are recommended to confirm the construct validity and test its reliability, as well as studies associating the number of hours of pediatric nursing for each category of care.

11. Dini AP, Guirardello EB. Construction and validation of an instrument for classification of pediatric patients. Acta Paul Enferm. 2013;26 (2):144-9.

12. Dini AP, Fugulin FM, Veríssimo MLO, Guirardello EB. Pediatric Patient Classification System: construction and validation of care categories. Rev Esc Enferm USP. 2011; 45(3):575-80.

13. Gouveia MTO, Mendes MCS, Luz YPO, Silva GRF. Classificação de pacientes pediátricos em um hospital de ensino de Teresina. Rev RENE. 2010;11(n.esp):160-8.

14. Andrade S, Serrano SV, Nascimento MSA, Peres SV, Costa AM, Lima RAG. The evaluation of an instrument for pediatric oncology patient classification. Rev Esc Enferm USP [Internet]. 2012 [cited 2014 June 21];46( 4 ):816-21. Available from: http://www.scielo.br/pdf/reeusp/v46n4/en_05.pdf

15. Lynn MR. Determination and quantification of content validity. Nurs Res. 1986;35(6): 382-5.

16. Alexandre NMC, Coluci MZO. Validade de conteúdo nos processos de construção e adaptação de instrumentos de medidas. Ciênc Saúde Coletiva. 2011;16(7): 3061-8.

17. Hair JF, Anderson RE; Tatham RL, Black WC. Análise multivariada de dados. Porto Alegre: Bookman; 2009.

18. Figueiredo Filho DB, Silva Junior JA. Visão além do alcance: uma introdução à análise fatorial. Opin Pública. 2010;16(1):160-85.

19. Mello DF, Lima RAG. Technical attainment, practical success and practical knowledge: hermeneutical bases for child nursing care. Rev Latino Am Enfermagem. 2009;17(4):580-5.

20. Marquis BL, Huston CJ. Administração e liderança em enfermagem: teoria e prática. Porto Alegre: Artmed; 2010.
Correspondence addressed to: Edinêis de Brito Guirardello Rua Vital Brasil, 251 - Cidade Universitária Zeferino Vaz CEP 13083-888 - Campinas, SP, Brasil E-mail: guirar@fcm.unicamp.br 